\section{JOURNAL}

OF URBAN

\section{SOCIETY'S ARTS}

Volume 1 Nomor 2, Oktober 2014: 110-120

\title{
Eksistensi Seni Grafis Monoprint dalam Kesenirupaan
} Yogyakarta

\author{
Bayu Aji Suseno
}

Minat Utama Seni Grafis

Program Pascasarjana Institut Seni Indonesia Yogyakarta

Jl. Suryodiningratan No. 8, Yogyakarta 55143

Tlp.0274-419791, 085729082332,E-mail: alatpendengar@gmail.com

\begin{abstract}
ABSTRAK
Tujuan penelitian ini adalah ingin memahami persoalan yang muncul dalam eksistensi seni grafis monoprint seniman Yogyakarta. Pertanyaan yang diajukan (1) apakah cetak monoprint merupakan suatu bentuk penyimpangan terhadap kaidah seni grafis konvensional; (2) bagaimana pengaruh booming lukisan dalam keberadaan praktik seni grafis monoprint. Keberadaan praktik monoprint sejalan dengan perkembangan seni rupa kontemporer yang merespons kekayaan teknik dan medium baru, yang disertai dengan konsep pemikiran seniman yang lebih plural. Namun, proses kreatif pegrafis tersebut seringkali dipandang kritis dan sinis oleh sebagian pihak karena karya yang dihasilkan oleh seniman tidak hanya ada satu edisi (eksklusif) seperti lukisan. Dalam rentang waktu tahun 2008 sampai 2011, beberapa seniman yang bermukim di Yogyakarta mengadakan pameran tunggal seni grafis monoprint. Kota Yogyakarta memiliki sejumlah seniman muda yang menekuni praktek cetak tersebut, antara lain: Andre Tanama, Ariswan Adhitama, Irwanto Lentho, dan T.A Sitompul. Hasil penelitian ini menunjukkan bahwa praktik seni grafis monoprint ternyata mampu bersaing dengan lukisan. Pengaruh booming lukisan menjadikan seni ini bukan lagi merupakan satu pencarian jati-diri, namun sebagai satu alternatif bentuk komoditas dengan label seni rupa modern.
\end{abstract}

Kata kunci: monoprint, seni grafis kontemporer, pegrafis Yogyakarta

\begin{abstract}
The Existence of Monoprint Art in Yogyakarta. The existence of monoprint practice grows in line with the development of the contemporary art that responds the invention of new techniques and media accompanied by the artists' more pluralistic thinking. Unluckily, the creative process of the monoprint artist is often critically judged and cynically looked at by some people because the work produced by the artist is only one edition (exclusive), just like painting. From 2008 to 2011, several artists living in Yogyakarta held a solo exhibition of monoprint. Yogyakarta has a number of young artists who devote their life to practice the art of printing, among others are Andre Tanama, Ariswan Adhitama, Irwanto Lentho, and TA Sitompul. This study is intended to find out whether monoprint making practice is considered as a deviation of the graphic art conventional rules and how the painting booming influences the monorprint existence. From the analysis, it can be inferred that a monoprint is capable of competing a painting and the booming of painting is no longer considered as a search of identity but more as an alternative of commodity form with the label of modern visual art.
\end{abstract}

Keywords: monoprint, contemporary graphic art, printmaker of Yogyakarta 


\section{Pendahuluan}

Seni grafis merupakan penggubahan gambar bebas karya perupa menjadi cetakan melalui proses manual dan menggunakan material tertentu dengan tujuan membuat perbanyakan karya dalam jumlah tertentu (Susanto, 2002:47). Teknik seni grafis secara garis besar dapat dikategorikan menjadi empat teknik utama, yakni, cetak datar, cetak tinggi (relief), cetak saring (serigrafi), dan cetak dalam (intaglio). Seni grafis merupakan cabang seni yang memberikan banyak ruang eksploratif yang dapat dimanfaatkan seniman sehingga dapat mencapai sebuah estetik tertentu serta memiliki karakter yang khas. Kematangan sebuah karya seni grafis dapat dinilai dari kualitas eksplorasi teknis sang seniman dan ide yang ditampakkan. Seni grafis, seperti halnya semua cabang seni adalah secara sadar menggunakan keterampilan dan imajinasi kreatif untuk menciptakan objek-objek estetik (Supriyanto, 2005: 4).

Sejarah menyebutkan bahwa seni grafis lahir dari kebutuhan-kebutuhan untuk memropagandakan gerakan politik kemerdekaan Indonesia khususnya pada dasawarsa 1940-an. Dalam hal ini perlu mengingat eksplorasi seni yang dilakukan Affandi, Abdul Salam, Suromo, Baharuddin Marasutan, dan Mochtar Apin (Sabana, 2005: 5). Propaganda dalam seni grafis nampak pada beberapa karya seniman seperti Mochtar Apin, Sudjana Kerton, dan Poppo Iskandar yang menekuni studi visual menggunakan teknik cetak, baik dalam pendekatan naturalis maupun abstraksi yang merebak luas di dunia. Keberadaan seni grafis pada awal kemerdekaan Indonesia dinilai sebagai tenggat waktu eksplorasi para seniman untuk mendalami dan menyerap ilmu memakai teknik cetak grafis. Jejak perkembangan seni grafis modern Indonesia dapat diketahui sejak kelahiran Republik Indonesia dengan karya-karya yang secara estetik bermutu. Seni grafis menjadi media politik di mana dengan lantang menggemakan suara heroisme, patriotisme, pergulatan artistik dan kecerdikan mengakali situasi yang ada saat itu melalui pahatan lino (Supriyanto, 2005: 4).

Keberadaan cabang seni cetak di Yogyakarta dalam kancah kesenirupaan tidak terlepas dari jalinan sejarah dan pertumbuhan kesenian yang turut melahirkan spirit kota itu tersendiri. Hal ini membentuk sebuah predikat sebagai salah satu barometer kesenian di Indonesia. Perkembangan seni grafis Yogyakarta dipengaruhi oleh tokohtokoh, peristiwa-peristiwa, semangat, pemikiran, teknik, gaya, dan nilai-nilai yang dilatarbelakangi oleh persoalan sosial, budaya, ekonomi, politik, dan ideologi. Salah satu bentuk karya seni rupa yang lahir dari kota ini adalah seni grafis. Beberapa tokoh seni grafis yang dikenal mencetuskan dan membangun pencitraan seni grafis Yogyakarta awal adalah seniman seperti Affandi, Suromo, dan Abdul Salam (Wulandari, 2008: 128).

Pegrafis yang bermukim di Yogyakarta memiliki kemampuan mumpuni dalam mengolah karya seni grafis dibandingkan dengan seniman di kota lain. Hal ini dapat ditemui dari superioritas mereka yang selalu menggondol predikat pemenang dalam setiap penyelenggaraan kompetisi atau pameran seni grafis, seperti Trienal Seni Grafis Indonesia tahun 2003, 2006, dan 2009. Yogyakarta mampu menghasilkan seniman yang cukup dominan dalam peta seni rupa Indonesia sehingga tidak berlebihan kalau disebut wajah seni rupa Yogyakarta adalah cermin wajah seni rupa Indonesia (Fadjri, 2000:4). Mereka mayoritas bergerak dari ruang akademik seni Institut Seni Indonesia Yogyakarta. Perguruan tinggi tersebut banyak mencetak pegrafis muda dalam percaturan kesenirupaan di Indonesia. Keistimewaan seniman di Yogyakarta adalah mampu melahirkan karya seni grafis yang cukup baik secara teknik maupun aspek visual, meskipun pola kerja mereka mengolah karya seni grafis seringkali bagi sebagian pihak dianggap sebagai suatu bentuk penyimpangan dari kaidah konvensional. Enin Supriyanto dalam Setengah Abad Seni Grafis Indonesia (2005) menyatakan bahwa Yogyakarta melahirkan para pegrafis yang berbakat serta memiliki pencapaian teknis cukup baik, meskipun mereka mempunyai peralatan cetak yang tidak lengkap dibandingkan Bandung.

Kota Yogyakarta memiliki sejumlah seniman yang menekuni praktik seni grafis monoprint. Hal ini dapat diamati dari penyelenggaraan pameran kelompok dengan mengusung tema Monoprint In Between Stream di Galeri Art District, Jakarta 


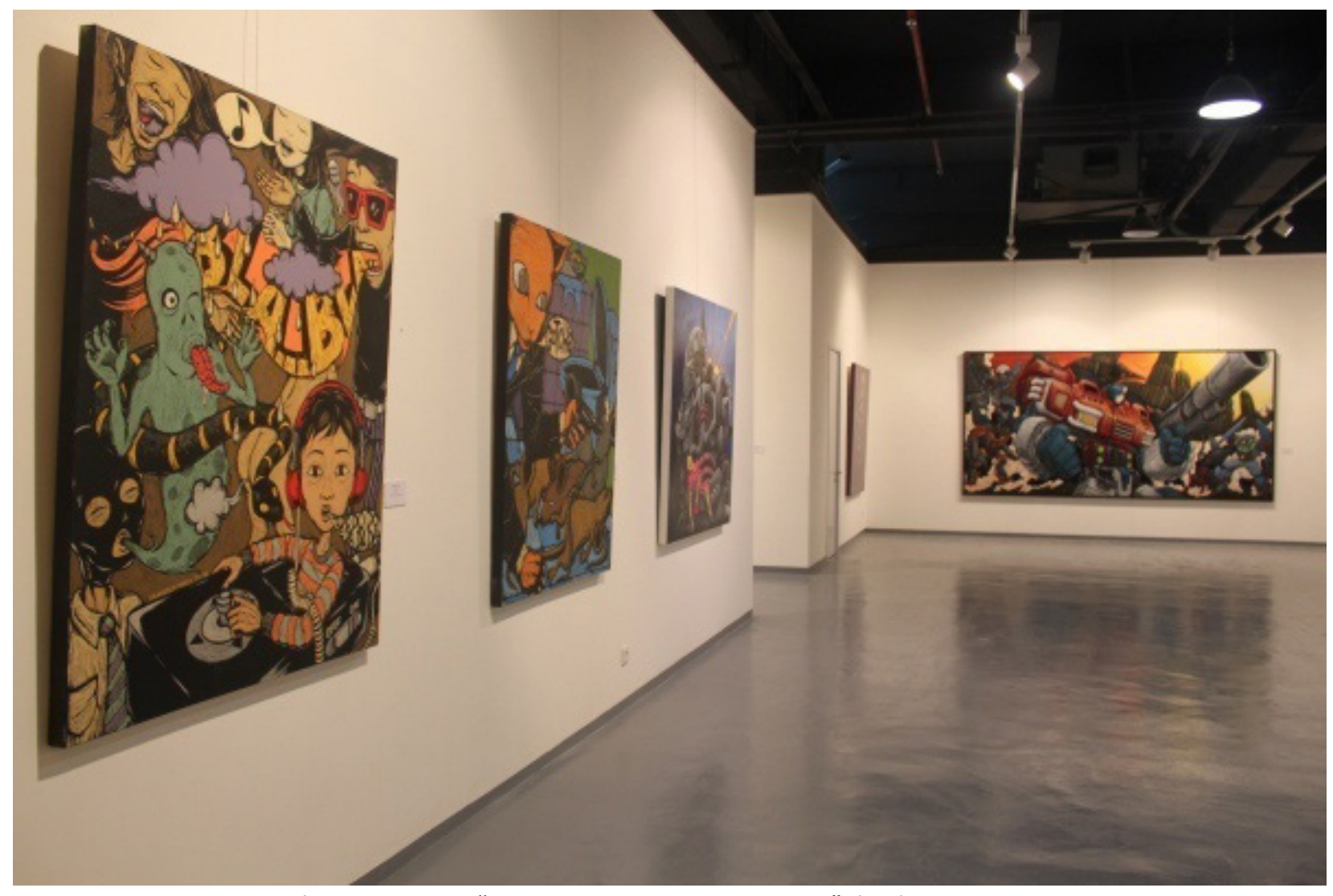

Gambar 1. Pameran "Monoprint in Between Stream" di Jakarta Art District.

(Sumber: http://www.outoftheboxindonesia.wordpress.com. Diakses pada 1 Januari 2013, pukul 16.22 WIB)

pada 25 Maret - 4 April 2010 (lihat gambar 1). Dalam pameran tersebut diikuti oleh sebelas pegrafis dengan latar belakang akademisi Institut Seni Indonesia (ISI) Yogyakarta, antara lain Agus Yulianto, A.C. Andre Tanama, Ariswan Adhitama, Anggara Tua Sitompul, Daniel Cahya Krisna, Fransisco Panca Nugraha, Irwanto Lentho, Sri Maryanto, Sutrisno, Teguh Hariyanta, dan Theresia Agustina Sitompul. Sementara tiga orang lainnya berasal dari Institut Tinggi Bandung (ITB), yakni Tisna Sanjaya, Syaiful Aulia Garibaldi, dan Sigit Purnomo Adi. Para pegrafis tersebut hanyalah sebagian dari pegrafis independen dan liberal yang enggan terkungkung dengan tradisi dan konvensi seni grafis, yang selalu mengharuskan karya seni grafis dicetak dengan sejumlah edisi yang tercetak sama atau persis.

Penelitian ini membahas beberapa seniman yang produktif mengolah karya seni grafis monoprint. Jumlah seniman dengan karya seni grafis monoprint terbilang cukup banyak sehingga tentu saja terdapat argumen yang kuat mengapa beberapa seniman dipilih sebagai studi kasus. Tidak bisa disangkal bahwa eksistensi seorang pegrafis pada beberapa kurun waktu terakhir menjadi pertimbangan sebagai subjek penelitian, karena ditinjau dari aktivitas berkeseniannya yang mampu menjadi sumber inspirasi bagi seniman lain dalam lingkup medan sosial kesenirupaan. Di Yogyakarta antara rentang waktu tahun 2008 sampai 2011, beberapa seniman mengadakan pameran tunggal karya seni grafis dengan cetak monoprint, yakni Andre Tanama, Ariswan Adhitama, Tuan Anggara Sitompul, dan Irwanto Lentho. Mereka merupakan seniman muda yang selama ini mampu menjaga konsistensi berkaryanya dengan seni grafis, meskipun perkembangan cabang seni cetak seringkali masih terkendala persoalan teknis dalam menembus persoalan apresiasi publik dan pasar seni rupa.

\section{Eksistensi Seniman Yogyakarta dalam Pameran Tunggal Seni Grafis Monoprint}

Rutinitas pameran tunggal atau kelompok seniman seni grafis monoprint yang diadakan beberapa tahun terakhir dapat menjadi pijakan 
pertumbuhan cabang seni cetak dalam ranah kesenirupaan di Yogyakarta. Dalam kurun waktu tahun 2008-2011 terdapat lima seniman yang mengadakan pameran tunggal seni grafis monoprint, antara lain: A.T Sitompul "Psyco-Visual" (2008); Pameran ini diadakan di Tembi House of Culture Yogyakarta pada 25 Januari-10 Februari 2008 (lihat gambar 2). Dalam pameran ini, Tompul menyajikan 15 karya seni grafis melalui cetak monoprint dengan teknik cukil kayu serta teknik pewarnaan handcolouring. Pameran ini mengusung gaya seni optik melalui pencapaian teknik seni grafis dengan mengolah garis sebagai upaya untuk mengugah daya visual maupun gejala psikologis manusia. Warna merah dalam karya Tompul merupakan elemen dan pusat perhatian (point of interest) dalam karya-karya yang dipamerkan, di samping sebagai penggambaran atau simbol bahwa 'merah' adalah jiwa, spirit kerja dan keberanian. Jika Optical Artist kebanyakan memakai teknik cetak saring atau silkscreen dengan penggunaan warnawarna komplemen (hijau versus kuning, biru versus orange, merah versus violet), perupa Tompul memakai scraper dan cukil kayu di atas hardboard cut sebagai media berkaryanya. Penggabungan dua teknik itu sendiri memerlukan kecermatan, akurasi, dan keterampilan teknis yang tinggi.

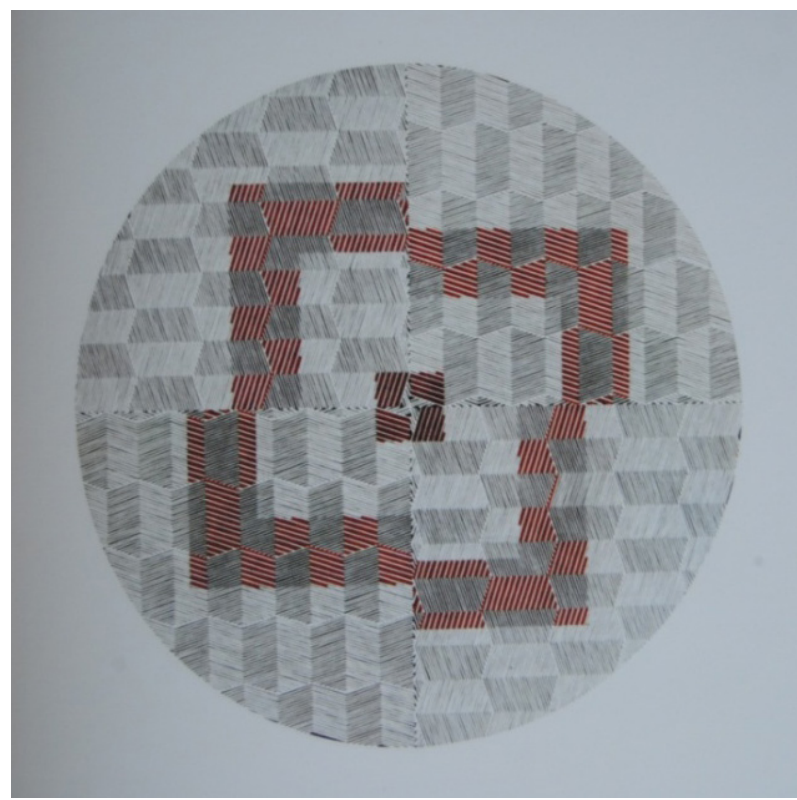

Gambar 2. A.T Sitompul "Nitipake Awak" 2008. Hardboardcut, Handcolouring, Monoprint on Canvas, $135 \times 135$ cm. (Sumber: Katalog Pameran Tunggal A.T Sitompul "Psycho Visual" 2008)
Seniman lain adalah Andre Tanama. Ia mengikuti pameran "Touch of Heaven" (2009) dan "The Tales of Gwen Silent" (2011). Pameran "Touch of Heaven" diadakan di Bentara Budaya Yogyakarta pada tahun 2009. Dalam pameran ini Andre Tanama menampilkan 17 karya seni grafis monoprint dengan teknik cukil kayu serta perwarnaan handcolouring. Namun dari total 32 buah karya Andre Tanama yang disajikan dalam pameran tersebut beberapa di antaranya lukisan dan patung. Dalam pameran tersebut, ia menghadirkan bentuk karak-ter gadis kecil bernama Gwen yang juga diambil dari nama putrinya Gwen Sai Ilen Tanama (gambar 3). Dengan mengusung refleksi perjalanan dari kehidupannya, perupa Andre memaknai berkaryanya sebagai sebuah proses spiritual karena merupakan karunia dari Tuhan. Kemudian The Tales of Gwen Silent merupakan pameran kedua Andre Tanama yang diadakan di Bentara Budaya Yogyakarta pada 28 Februari-3 Maret 2011. Seperti sebelumnya ia masih menampilkan karya seni grafis dengan teknik monoprint dan sejumlah karya lukis dan patung. Dalam pameran ini Andre Tanama menceritakan

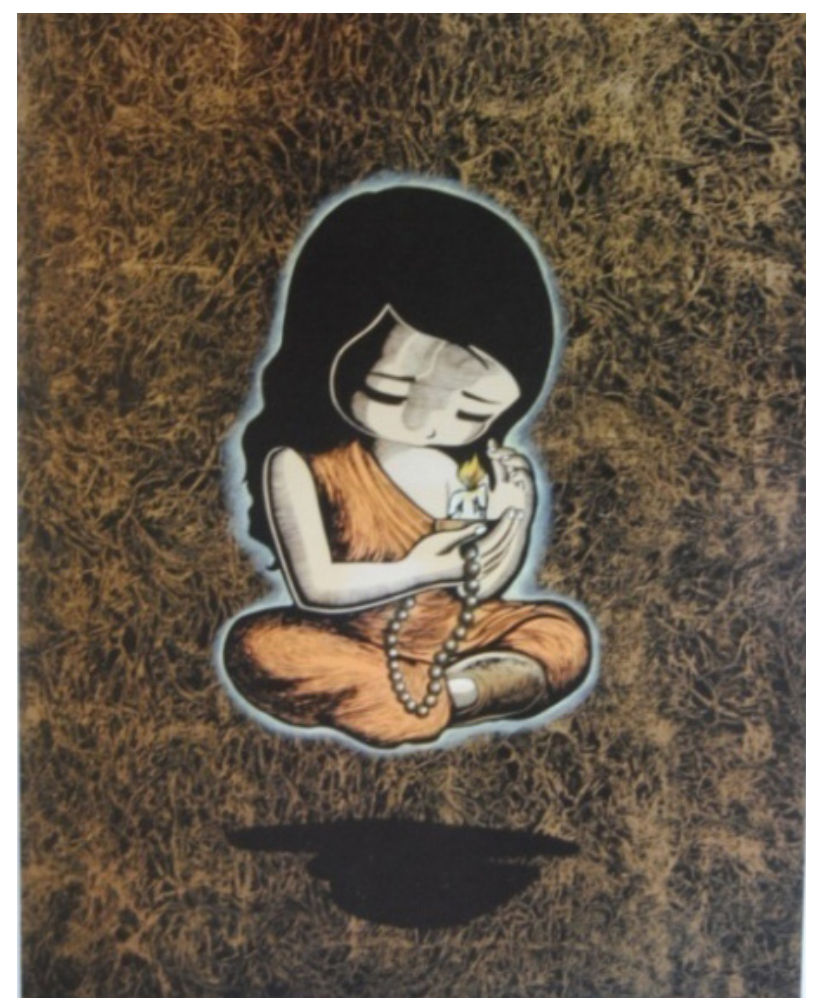

Gambar 3. Andre Tanama "The Prayer" 2008 Hardboardcut, Handcolouring, Monoprint on Canvas, $200 \times 145$ cm. (Sumber: Katalog Pameran Tunggal Andre Tanama "Touch of Heaven" 2009) 
sisi lain tentang kisah anak-anak di belahan dunia lain yang masih satu masa dengan figur Gwen Silent. Andre menampilkan Gwen Silent sesosok gadis kecil yang berumur kira 4-5 tahun, di mana tokoh tersebut digambarkan tidak memiliki mulut dengan mata yang selalu terpejam.

Pegrafis ketiga adalah Ariswan Adhitama. Ia mengikuti pameran "In Repair" (2010). Pameran ini diadakan di Bentara Budaya Yogyakarta pada tanggal 3-12 Desember 2010 (gambar 4). Dalam pameran ini, Ariswan memamerkan sekitar 11 karya seni grafis melalui cetak monoprint dengan teknik cukil kayu serta teknik perwarnaan handcolouring. Ariswan memilih bentuk robot sebagai perwujud-an dalam karyanya melalui teknik cukil kayu dan pewarnaan handcolouring. Bagi perupa Ariswan Adhitama karakter robot merupakan pemaknaan representasi yang mudah untuk dipahami serta sekaligus menjadi metafora visual dengan menceritakan tentang kehidupan dirinya. Dibandingkan dengan para pegrafis lainnya ukuran karya seni grafis monoprint Ariswan relatif cukup besar. Ia membuat sendiri sistem kento (sistem pencetakan ulang) agar image cetakan yang dihasilkan lebih presisi. Dengan mekanisme kerja tersebut, ia mampu menghasilkan karya grafis monoprint full-colour berukuran besar, seperti karya yang berjudul Green Convergence berukuran 195x700 cm (gambar 5). Karya tersebut ditampilkan dalam pameran tunggal Ariswan dan tercatat sebagai karya monoprint terbesar yang pernah dibuat oleh seniman Indonesia.

Irwanto Lentho menampilkan pameran "Sang Pencukil" (2011). Pameran ini diadakan di Bentara Budaya Yogyakarta pada 3-11 Agustus 2011 (gambar 6). Dalam pameran ini, Irwanto menampilkan 16 karya cetak seni grafis melalui

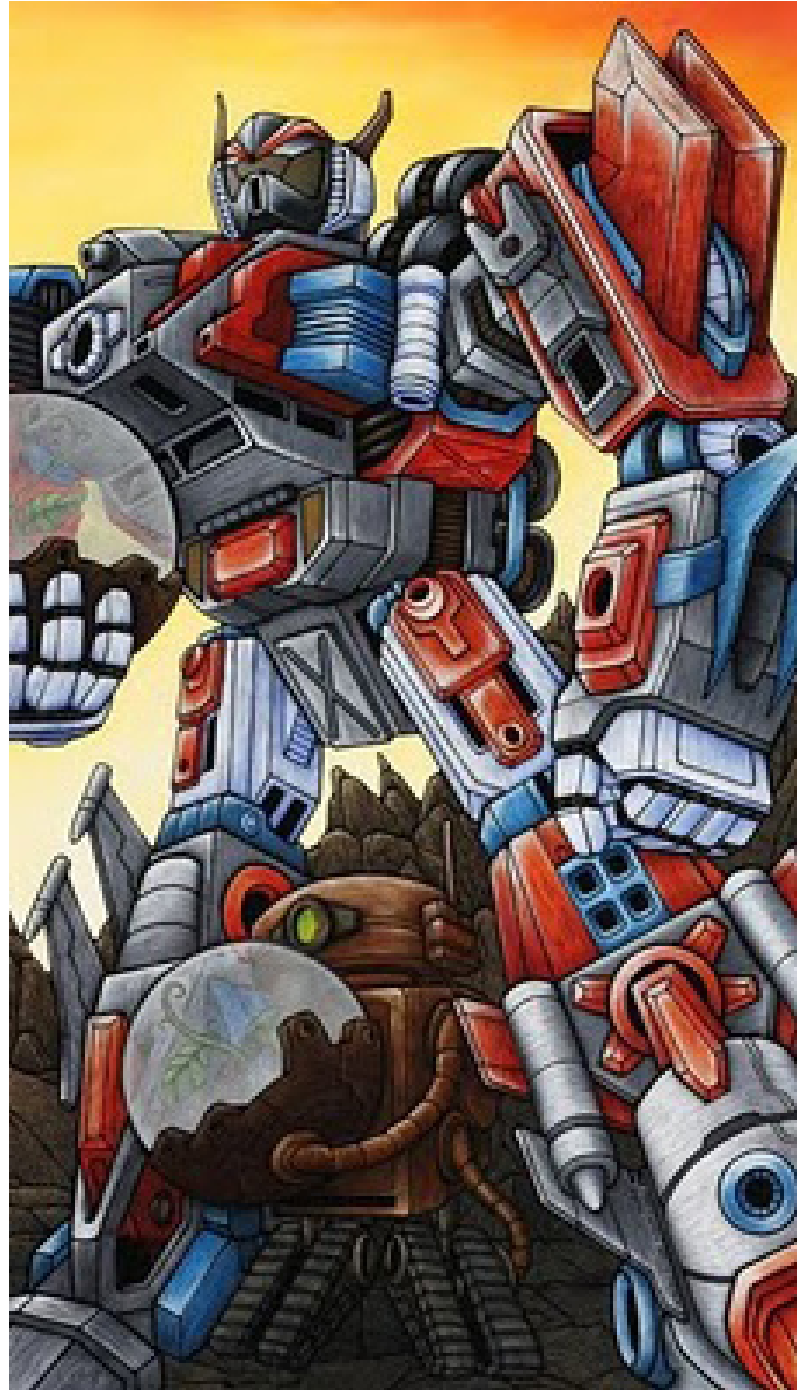

Gambar 4. Ariswan Adhitama "Grow in Limitedness" 2010. Harboardcut, Handcolouring, Monoprint on Canvas, 200 x $150 \mathrm{~cm}$. (Sumber: Katalog Pameran Tunggal Ariswan Adithama "In Repair" 2010)

cetak monoprint dengan teknik cukil kayu dan teknik pewarnaan handcolouring. Dengan mengusung tema mengenai pandangan personalnya terhadap dunia sekitarnya, Irwanto memakai metafora boneka berbentuk binatang dan manusia yang dikendalikan oleh sejumlah tali, kemudian

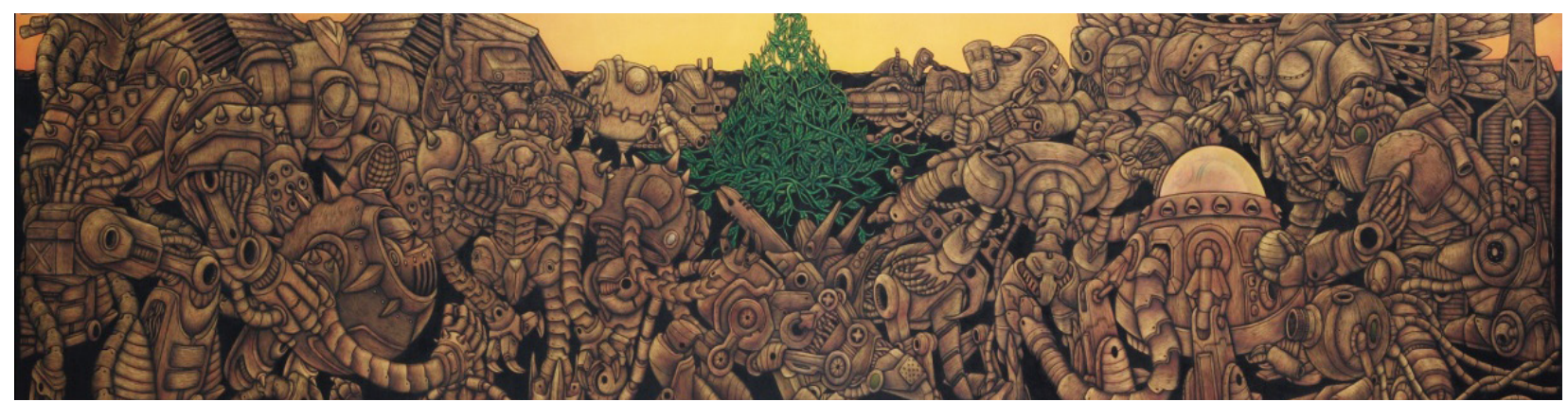

Gambar 5. Ariswan Adhitama "Green Convergence" 2010. Harboardcut, Handcolouring, Monoprint on Canvas, $195 \times 700$ cm. (Sumber: Katalog Pameran Tunggal Ariswan Adithama "In Repair" 2010) 


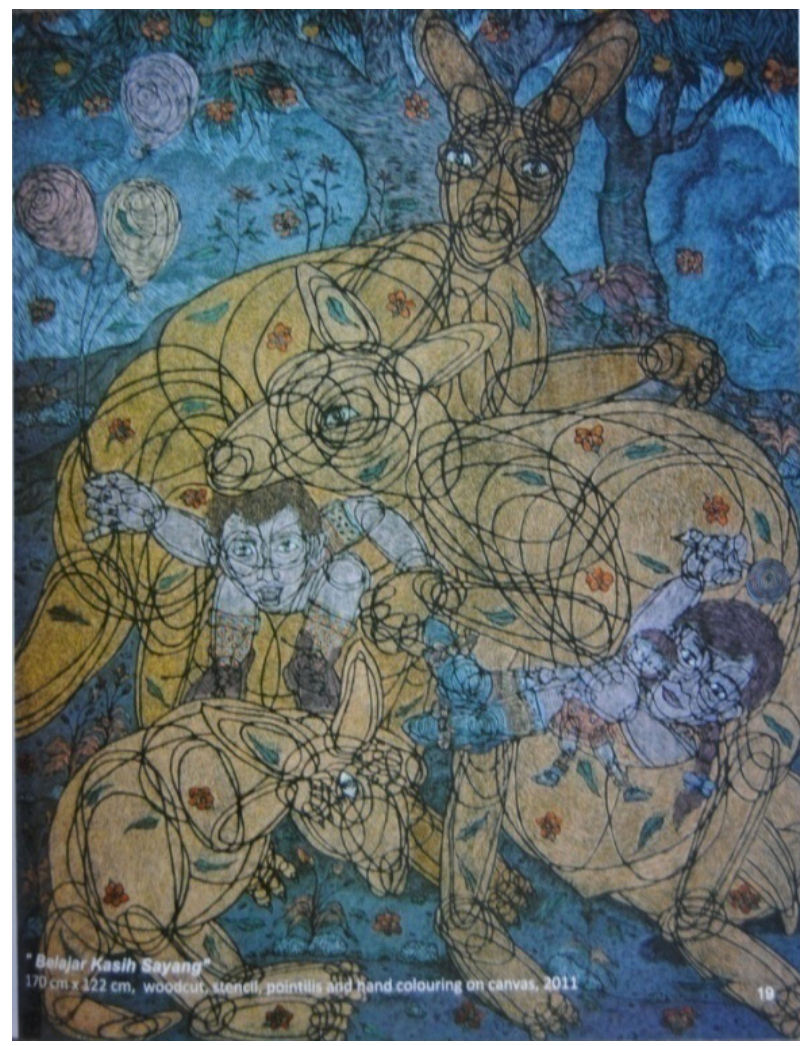

Gambar 6. Irwanto Lento "Belajar Kasih Sayang" 2010 Harboardcut, Handcolouring, Monoprint on Canvas, $200 \times 150 \mathrm{~cm}$. (Sumber: Katalog Pameran Tunggal Irwanto Lentho "Sang Pencukil" 2011)

menjadikan sebuah kontrol manipulatif dari 'seseorang di balik layar' atau dikenal dengan dalang. Irwanto banyak mencantumkan boneka dalam karya grafisnya sebagai ungkapan-ungkapan satir yang berhubungan kuat dengan kehidupan sosial masyarakat sehari-hari. Irwanto Lentho merupakan seorang pegrafis yang mengidentifikasi dirinya sebagai pencukil. Baginya istilah penyukil berarti setara dengan pelukis, pemahat atau pematung. Namun, di luar konotasi tersebut 'Sang Pencukil' secara implisit menyarankan sebuah pernyataan sikap yang hendak menegaskan posisinya dalam medan sosial kesenirupaan.

\section{Penyimpangan Teknik Konvensional dalam Seni Grafis Monoprint}

Hadirnya paradigma seni rupa kontemporer di Yogyakarta memberikan persentuhan baru, baik dalam praktik maupun wacana teorinya, demikian juga dalam seni grafis. Fenomena yang terjadi diikuti oleh munculnya karya seni grafis dengan merespons kekayaan teknik dan medium baru disertai konsep pemikiran seniman yang lebih plural. Kedudukan cabang seni cetak dalam pertumbuhan seni rupa kontemporer tidak hanya keterkaitan dengan konsep ide atau gagasan seniman yang situasional, namun mengalami perluasan cara kerja visual dari sebelumnya yang bersifat konvensional menuju pola kerja nonkonvensional. Praktik kerja seni grafis dalam ranah kontemporer kiranya dinilai amat berkembang dengan baik karena menguntungkan seniman dari segi teknik maupun konseptual. Selain itu, juga keberanian seniman untuk mengeskplorasi teknis dan medium baru yang dianggap kurang lazim dalam penyajian karya seni grafis. Seni rupa kontemporer juga diartikan sebagai karya seni yang merupakan jawaban atas masalah-masalah yang muncul dalam praktik dan perilaku artistik yang menyimpang dari konvensi sebelumnya (Susanto, 2004:16).

Penyimpangan terhadap kaidah konvensional dapat ditelusuri dari pengerjaan karya monoprint (cetak tunggal). Monoprint adalah sarana produksi cetak tunggal dari suatu gambar (Palmer, 1975:7). Jika kode etik seni grafis konvensional bersifat reproduktif atau dapat diproduksi dengan jumlah yang sangat banyak, praktik kerja monoprint seniman hanya membuat karya seni grafis dalam satu edisi. Sulit melacak latar belakang perkembangan monoprint di Indonesia. Hal ini mengingat keberadaan metode cetak tersebut memang terbilang baru dan cukup populer di kalangan pegrafis muda semenjak bergulirnya booming seni rupa. Proses berkesenian seperti ini ternyata jauh sebelumnya sudah terlebih dahulu diterapkan oleh seniman seni grafis pada masa lampau. Inda Critaninda Noerhadi (2012: 83) menjelaskan bahwa karya cetak grafis dari masa renaissance sudah dibatasi jumlahnya karena diciptakan langsung oleh senimannya bukan dipesan oleh peminat seni atau kolektor. Teknik ini sampai sekarang masih digunakan khusus untuk seni grafis karena tujuan utamanya bukan lagi untuk membuat karya seni cetak dalam jumlah yang besar.

Seniman Yogyakarta menerapkan pewarnaan handcolouring dalam pembuatan seni grafis monoprint melalui cukilan kayu (hardboard cut) dengan dimensi karya berskala besar. Namun, pewarnaan handcolouring tidak dibuat melalui 
teknik cetak, tetapi dengan goresan kuas (manual) seperti halnya lukisan. Hal ini berbeda dengan teknik pewarnaan karya seni grafis secara konvensional melalui multi-plat atau pendekatan reduksionis. Jika multi-plat mengunakan papan atau screen yang diberi warna secara terpisah, pendekatan reduksionis proses pengerjaannya dengan menumpuk warna terang kemudian diteruskan ke warna yang lebih gelap. Dalam perkembangan seni grafis memang identik dengan dicetak pada permukaan kertas karena seni ini sangat tergantung pada pemakaian kertas karena medium cetak ini memiliki kelebihan bersifat massal. Seiring dengan perkembangan praktik kerja monoprint yang hanya membuat image tunggal sehingga membuat para pegrafis mulai mempertimbangkan kanvas sebagai medium cetak karya seni grafis. Di satu sisi, penggunaan medium kanvas sebagai medium cetak untuk menunjukkan karya grafis agar layak dikoleksi serta dapat diandalkan eksistensinya. Aminuddin T.H. Siregar (Sabana, 2005: 107) menyatakan bahwa penggunaan medium kanvas dikenal lebih tahan terhadap hasil cetakan juga tidak dipungkiri meningkatkan nilai ekonomisnya. Kertas di samping keberadaannya secara institusional untuk membedakan antara karya seni grafis dengan lukisan. Kanvas dimitoskan sebagai representasi keagungan, kelanggengan, orisinalitasnya, adilubung, auratik, dan merefleksikan pesona serta gairah zaman.

Selintas penyajian karya seni grafis monoprint cenderung menyerupai lukisan karena tidak mencantumkan keterangan edisi cetak. Dalam kode etik seni grafis selalu menampilkan edisi cetak yang terletak di bagian bawah di luar gambar. Keterangan edisi cetak memuat tanda tangan seniman, tahun pembuatan, judul karya, nomor urut cetak, dan jumlah edisinya, misalnya; 10/25 berarti karya tersebut merupakan cetakan ke-10 dari jumlah seluruhnya 25 edisi. Standardisasi dalam prosedur seni grafis konvensional melalui pencantuman keterangan edisi cetak sudah berlaku secara global dan tidak mengurangi nilai orisinalitasnya. Pentingnya perlindungan hak cipta atas karya seni cetak telah digunakan oleh Albrecht Durer. Ia merupakan seniman yang pertama kali membubuhkan tanda tangan dan tanggal pembuatan karya seni cetaknya. Hal ini dilakukan untuk menghindari pemalsuan terhadap karya seni cetaknya dalam kegiatan bisnis. Kemudian, dari produksi serial dari karya seni cetaknya juga ditujukan bagi peminat atau kolektor agar harganya lebih terjangkau (Noerhadi, 2012:84).

Secara aspek visual seni grafis monoprint keberadaannya ternyata mampu bersaing dengan lukisan, meskipun praktik seniman tersebut dianggap sebagai penyimpangan terhadap kaidah konvensional. Karya seni grafis monoprint merupakan produk dari kerja kreatif yang dihasilkan oleh pegrafis karena mereka tidak mau terkungkung dengan tradisi atau konvensi seni grafis yang selalu mengharuskan karya grafis murni dicetak dalam sejumlah edisi. Pembuatan karya seni grafis konvensional yang dinilai rumit dan membutuhkan praktik kerja sistematis seringkali mengakibatkan seniman mengalami kesulitan dalam pencapaian teknis perwujudannya sehingga wajar apabila seniman tidak tunduk pada nilainilai tradisi dalam seni grafis. Dengan menyiapkan sendiri sistem dan mekanisme kerja yang sesuai dengan apa yang dibutuhkan dalam menghasilkan karya seni grafis, proses kreatif seniman tersebut dipandang dari sudut profesionalnya dianggap ngawur. Seniman merupakan individu yang bebas karena bisa melepaskan diri dari belenggu tradisi nilai seni di masyarakatnya, lantaran nilai-nilai itu sudah tidak sesuai dengan kebutuhan keadaan yang seharusnya (Sumardjo, 2000: 89).

Dalam permasalahan konvensi seni grafis yang belum baku, setiap seniman bebas untuk menerapkan proses kreatifnya. Proses kreatif seniman merupakan rangkaian kegiatan yang menciptakan dan melahirkan karya seni sebagai ungkapan gagasan dan keinginannya. Proses kreatif seniman pada hakikatnya merupakan usaha dalam memodifikasi mengubah atau memperbaharui sesuatu yang telah ada sebelumnya. Di situlah seniman berupaya dengan keras menampilkan sesuatu yang lain dari apa yang sudah ada sehingga melahirkan suatu realitas baru yang kemudian diakui sebagai hasil ciptaannya. Camus dalam Seni Politik, Pemberontakan menyatakan bahwa kreativitas dan pemberontakan memiliki keterkaitan yang sama. Sebagian besar tindakan kreatif umumnya 
merupakan suatu bentuk pemberontakan terhadap tatanan lama. Demikian juga sebaliknya, dalam pemberontakan terkandung usaha-usaha kreatif, sehingga keduanya merupakan perjuangan untuk membebaskan diri dari batasan tatanan yang ada atau dianggap usang dengan mencari alternatifalternatif baru yang lebih sesuai dengan kebutuhan. Djelantik (1999: 80) mengatakan kreativitas menyangkut penemuan sesuatu yang "seni" nya belum pernah terwujud sebelumnya. Apa yang dimaksud dengan "seni" nya tidak mudah ditangkap karena ini menyangkut sesuatu yang prinsipil dan konseptual, yang dimaksudkan bukanlah hanya "wujud" yang baru, tetapi adanya pembaharuan dalam konsep-konsep estetikanya sendiri, atau penemuan konsep yang baru sama sekali.

Selain itu, pegrafis dalam menghasilkan karya seni yang berkualitas dari segi teknik dan konseptual memiliki modal berkesenian. Modal tersebut menurut pandangan Piere Bourdie (1983) disebut modal budaya (cultural capital) yang meliputi pendidikan, intelektualitas, keterampilan, dan keahlian. Melalui modal kultural inilah sesungguhnya akan lahirlah manusia-manusia yang mempunyai daya pikir progresif untuk melahirkan sebuah pemikiran dan karya seni yang menggugah. Pembentukan arena produksi kultural, selain modal budaya juga terdapat modal simbolis yang berkaitan dengan kelas sosial. Modal kultural dapat ditinjau dari latar belakang pegrafis yang pernah mengenyam pendidikan bidang seni, sedangkan modal simbolis mereka dalam medan sosial seni disebut seniman akademis. Modal kultural seniman melalui pendidikan bidang seni, yakni mendapatkan wacana, pengetahuan, dan keahlian sebagai patokan dalam menciptakan sebuah karya seni. Dengan predikat seniman akademis yang melekat dalam proses berkesenian mereka, kemudian menjadikan salah satu faktor penerimaan karya seni grafis dalam kancah kesenirupaan di Indonesia. Kehadiran karya seni seniman akademis menumbuhkan suasana intelektualitas berkesenian yang merupakan manifestasi dari modal cultural. Meskipun demikian, praktik berkesenian seniman akademisi seringkali melahirkan karya seni yang tidak 'tertib' dalam kaidah konvensional seperti halnya karya seni grafis monoprint.

\section{Dampak Booming Lukisan dalam Kelahiran Seni Grafis Monoprint}

Pada paruh tahun 2007 jagat seni rupa Indonesia kembali mengalami booming atau peningkatan tiba-tiba harga lukisan yang seringkali mengalami peningkatan secara tidak wajar. Kali ini ada beberapa ciri yang menyerupai dengan fasefase sebelumnya, harga lukisan melejit tinggi, pasar seperti tidak terkendali dan liar.

Dampak booming seni rupa ditandai dengan peningkatan jumlah dan frekuensi pameran, pertumbuhan galeri komersial, bertambahnya kolektor karya seni, dan kegiatan lelang karya seni rupa. Di samping itu keberadaannya galeri bukan hanya sebagai ruang pamer, melainkan juga mampu menjadi dealer seni yang menghubungkan seniman dengan kolektor sehingga memicu pertumbuhan pasar seni rupa. Pemicu booming seni rupa juga tidak terlepas dari pengaruh faktor ekonomi yang masih memiliki sangkut pautnya dengan masyarakat modern. Seni rupa dengan label modern terus bergulir, sampai pada gilirannya seni ini bukan lagi merupakan satu pencarian jati-diri, namun kemudian sebagai satu alternatif bentuk komoditas. Norma seni bermula sebagai satu perwujudan komunitas beralih ke bentuk komoditas, bahkan sampai pada titik puncak tertentu seni merupakan bentuk investasi, muncullah "Boom Seni Rupa Indonesia”. Seni berpindah dari monomentalitas kebutuhan spiritual beralih ke dalam dunia investasi (Kartika, 2004: 57).

Dalam paradigma boomingseni rupa cenderung menempatkan karya seni sebagai komoditas atau bernilai ekonomi semata. Komodifikasi (comodification) adalah proses yang diasosiasikan dengan kapitalisme di mana objek, kualitas, dan tanda-tanda diubah menjadi komoditas, yaitu sesuatu yang tujuan utamanya adalah untuk dijual di pasar (Barker, 2011:412). Piliang (2011: 21) mengatakan bahwa komodifikasi adalah sebuah proses menjadikan sesuatu yang sebelumnya bukan komoditi sehingga kini menjadi komoditi.

Gejala komodifikasi dapat dirujuk dari pemikiran Karl Marx bahwa akibat ekonomi uang yang berdasarkan semangat menciptakan keuntungan yang sebanyak-banyaknya mengakibatkan 
munculnya gejala komodifikasi di berbagai sektor kehidupan. Dalam catatan kesenirupaan Indonesia seni grafis hanya digunakan oleh seniman pribumi sebagai media propaganda melawan paham kolonialisme, dibandingkan dengan lukisan yang telah terlebih dahulu menjadi komoditas seni yang hanya dikonsumsi oleh bangsawan atau kaum elite. Seni grafis belum dipahami sebagai salah satu media seni yang otonom karena dipandang sebagai "perluasan kerja kreatif pelukis”. Praktik seni cetak digunakan oleh seniman untuk pembuatan poster perjuangan dan ilustrasi majalah, itupun sebatas cukilan kayu dan litografi. Para perintis dalam seni grafis adalah juga seorang pelukis atau ilustrator yang ternyata memiliki profesi rangkap, hal inilah yang mewarnai perjalanan seni grafis Indonesia.

Tidak dapat dipungkiri bahwa kemunculan seni grafis monoprint memang dipengaruhi oleh booming seni rupa terutama lukisan. Praktik reduplikasi cetak konvensional mengakibatkan eksistensi karya seni grafis di pasar tidaklah sesignifikan lukisan yang sifatnya tunggal, hal ini membawa nilai eksklusivitas di dalamnya. Pengaruh pasar yang dikuasai oleh kaum elite (kolektor) tentu menggemari dan memburu eksklusivitas demi menjaga prestige dari karya itu sendiri. Cabang seni cetak mulai menemukan momentum menembus industri (pasar) seni rupa setelah booming seni rupa 2007. Hal ini dapat ditelusuri dari pameran Seni Grafis Hari Ini yang diselenggarakan oleh Bentara Budaya pada tanggal 14-23 Juni 2008. Pameran ini diikuti oleh pegrafis senior, antara lain: Agus Prasetyo, Agus Yulianto, Sri Maryanto, Arief Eko Saputro, AC. Andre Tanama, Syahrizal Pahlevi, Tisna Sanjaya, Agung Kurniawan, Setiawan Sabana, dan Haryadi Suadi. Dalam Kompas edisi 15 Mei 2008 menyebutkan bahwa beberapa karya seni grafis sudah dinyatakan terjual dalam pameran itu, seperti karya pegrafis AC Andre Tanama berjudul The Flute Girl \#2 yang dibuat dengan teknik monoprint dicetak pada kanvas berukuran $145 \times 200 \mathrm{~cm}$, kemudian 2 (dua) buah karya Agus Prasetyo yang berjudul Freedom Energy berukuran 70 x 130 dan Manusia, Binatang, Tumbuh-tumbuhan, Benda-benda Aneh dan lainlain dengan ukuran $130 \times 140 \mathrm{~cm}$, kedua karya pegrafis Agus Prasetyo tersebut diciptakan melalui teknik cukilan kayu (hardboard cut) dan pewarnaan handcolouring yang dicetak pada medium kanvas. Estimasi harga karya seni grafis para pegrafis yang terjual dalam pameran itu mencapai kisaran harga dari 1 juta sampai 50 juta rupiah.

Terkait dengan konteks pasar seni rupa tidak hanya ditinjau dari perspektif seniman dalam menjual barang seni (the art of selling). Namun, bagaimana upaya seniman menciptakan sebuah karya seni karena memiliki komitmen serta idealisme berkesenian dalam medan sosial kesenirupaan. Dorongan seniman menghasilkan karya seni melalui proses kreativitas memang tidak hanya untuk memenuhi hasrat berkesenian atau nilai estetis karya tersebut, namun dari pengaruh faktor ekonomi dan strata sosial. Dalam pandangan estetika Monroe Beardsley (Sachri, 2002: 182) membahas proses kreatif dan dorongan penciptaan atau daya keilhaman muncul dalam diri seniman. Pertama adalah karena adanya dorongan kemanusiaan biasa, yaitu hasrat untuk mencapai kemashuran, uang, digandrungi, kekuasaan, dan lain sebagainnya. Dorongan-dorongan ini sebenarnya hampir berlaku bagi setiap orang, tetapi seniman memang mempunyai karakteristik sendiri yang perlu pengkajian lebih luas. Tentu sangat berbeda antara seniman yang baru mulai meniti kariernya dan seniman kawakan yang telah terkenal. Demikian latar belakang, baik kebudayaan, sosial, ekonomi, dan pendidikan sangat menentukan motivasi seorang untuk melakukan kegiatannya. Kedua, adalah dorongan yang bersifat rohani; yaitu kebutuhan-kebutuhan yang dirasakan oleh rohaninya secara mendalam bahkan mungkin tidak didasari. Dorongan seniman dalam menghasilkan karya seni bukan hanya untuk memenuhi hasrat berkesenian atau meningkatkan harkat martabat sebagai seniman tetapi juga dilatarbelakangi oleh faktor ekonomi.

Dalam perspektif Becker (1982), proses kreatif pegrafis melalui karya monoprint sehingga mampu mendapatkan dukungan dari berbagai pihak dari luar aktivitas berkeseniannya dapat dikategorikan sebagai Integrated Profesional Artist. Jenis seniman ini mempunyai karakter dan kecakapan diri yang luar biasa. Ia harus mampu mengoptimalkan segenap potensi yang dimiliki, baik potensi ke dalam 
(diri sendiri) ataupun potensi keluar (berkaitan dengan orang lain). Kecakapan teknik adalah kecakapan dasar yang harus dimiliki seniman. Hal ini berkaitan dengan teknis penciptaan karya dan aspek estetik. Dimulai dengan menemukan ide, mengolah gagasan, kemudian mengeksekusinya dalam sebuah karya seni yang menuntut kerajinan tangan seniman, hingga mekanisme sampai pada penyebarluasan karya agar dapat diapresiasi dengan baik oleh publik. Kemudian, kecakapan sosial juga diperlukan seniman untuk mendapatkan dukungan dari berbagai pihak di luar aktivitas berkeseniannya.

Supriyanto (2005) menjelaskan bahwa kelemahan yang terlacak dalam perkembangan seni grafis di Indonesia adalah kelemahan dalam menyiasati pasar seni rupa. Banyak orang yang beranggapan seni grafis tidak mampu bersaing dengan seni lukis dalam hal perebutan pasar. Karena hampir seni grafis dibuat dengan jumlah dengan skala yang cukup banyak, harganya tidak bisa "melejit" seperti lukisan. Karakter cetak seni grafis yang bersifat massal yang mengandung mekanisme reproduksi dianggap tidak orisinil, tidak tunggal, dan dianggap murahan dibandingkan dengan lukisan (Sabana, 2005: 108). Hal tersebut kemudian membuat pegrafis seperti halnya pelukis atau pematung harus bisa menjadi individu profesional dengan cara menjual karya mereka sebagai produk yang dihargai sehingga seniman seni grafis harus mampu meyakinkan para kolektor baik individual maupun institusional. Mungkin di sinilah permasalahan seni grafis yang selayaknya bukan menyasar pada kolektor pribadi, tetapi lebih pada sejumlah orang secara bersama sehingga diperlukan peranan "harga" karya seni grafis untuk menjembatani antara seniman dengan peminat (kolektor). Kekurangan informasi tentang perbedaan kedudukan karya lukisan terhadap karya seni grafis dapat mengaburkan kewajaran harga antara kedua jenis cabang seni tersebut. Dibutuhkan pasar seni untuk karya seni grafis yang dikenal print auction sehingga memberikan kesempatan bagi seniman atau kolektor seni grafis dalam menertibkan atau menyesuaikan harga dari setiap karya seni grafis yang diperjualbelikan dengan sewajarnya. Terciptanya situasi seperti ini akan lebih merangsang serta membuka kesadaran bagi semua pihak yang berkecimpung dalam cabang seni cetak, baik seniman maupun peminat (kolektor) termasuk lembaga seni (Pirous, 2003: 82).

\section{Simpulan}

Kota Yogyakarta memiliki seniman muda seni grafis yang produktif dan konsisten menekuni seni grafis cetak monoprint. Meskipun demikian, proses kreatif pegrafis tersebut seringkali dianggap sebagai penyimpangan terhadap konvensional seni grafis. Keberadaan karya monoprint dipengaruhi oleh booming seni rupa terutama lukisan. Hal ini dapat ditelusuri penyajiannya yang cenderung menyerupai lukisan, seperti tidak mencantumkan keterangan edisi cetak, teknik pewarnaan handcolouring, dan medium cetak kanvas. Praktik reduplikasi cetak konvensional yang tidak sesignifikan lukisan yang sifatnya tunggal membawa nilai eksklusivitas di dalamnya. Pegrafis seperti halnya pelukis atau pematung harus bisa menjadi individu profesional dengan cara menjual karya mereka sebagai produk yang dihargai. Perkembangan karya seni rupa yang dipengaruhi oleh kapitalisme pasar sehingga berdampak besar bagi perubahan pola dan produksi berkesenian seniman. Seni rupa dengan label modern terus bergulir, sampai pada gilirannya seni ini bukan lagi merupakan satu pencarian jati-diri, namun kemudian sebagai satu alternatif bentuk komoditas.

\section{Ucapan Terima Kasih}

Ucapan terima kasih kepada Prof. Dr. Dwi Marianto yang telah berkenan membimbing dalam penulisan tesis hingga terwujud artikel ini.

\section{Kepustakaan}

Barker, Chris. 2011. Cultural Studies; Teori \& Praktik. Yogyakarta: Kreasi Wacana.

Becker, Howard S. 1982. Art World. London: University of California Press.

Djelantik, A. A. M. 1999. Estetika (Sebuah Pengantar). Bandung: Masyarakat Seni Pertunjukan Indonesia.

Fadjri, Raihul. 2000. Yogya dalam Peta Seni Rupa 
Kontemporer Indonesia. Yogyakarta: Yayasan Seni Cemeti.

Kartika, Dharsono Sony. 2004. Seni Rupa Modern. Bandung: Rekayasa Sains.

Palmer, Frederick. 1975. Introducing Monoprints. New York: Drake Publishers.

Piliang, Yasraf Amir. 2011. Dunia yang Dilipat: Tamasya Melampaui Batas-Batas Kebudyaan. Bandung: Pustaka Matahari.

Pirous, A.D. 2003. Melukis itu Menulis. Bandung: Penerbit ITB.

Noerhadi, Inda Critaninda. 2012. Sejarah Hak Cipta Lukisan. Jakarta: Komunitas Bambu.

Supriyanto, Enin. 2005. Setengah Abad Seni Grafis Indonesia. Jakarta: Kepustakaan Populer Gramedia.

Sabana, Setiawan. 2005. Legenda Kertas. Jakarta: Kiblat.

Sachari, Agus. 2002. Estetika (Makna, Simbol, dan Daya). Bandung: Penerbit ITB.

Sumardjo, Jakob. 2000. Filsafat Seni. Bandung: Institut Teknologi Bandung.

Susanto, Mikke. 2002. Diksi Seni Rupa. Yogyakarta: Kanisius.

2004. Menimbang Ruang Menata Rupa. Yogyakarta: Galang Press.

Wulandari, Wiwik Sri. (2008), "Seni Grafis Yogyakarta dalam Wacana Kontemporer" dalam ARS, Jurnal Seni Rupa dan Desain Vol.
8 No. 2 September.

Yuliman, Sanento. 2001. Dua Seni Rupa (Serpihan

Tulisan Sanento Yuliman). Jakarta: Kalam.

\section{Katalog}

Pameran Tunggal A.T Sitompul "Psycho-Visual", Tembi House of Culture Yogyakarta, 25 Januari-10 Februari 2008.

Pameran Tunggal Andre Tanama "Touch of Heaven", Bentara Budaya Yogyakarta, 24-27 Desember 2010.

Pameran Tunggal T.A Sitompul "Alun dan Pusaran”, Bentara Budaya Yogyakarta, 22 30 Mei 2010.

Pameran Tunggal Ariswan Adhitama "In Repair", Bentara Budaya Yogyakarta, 3 - 12 Desember 2010.

Pameran Tunggal Andre Tanama "The Tales of Gwen Silent", Syang Art Space Magelang, 28 Februari - 3 Maret 2011.

Pameran Tunggal Irwantho 'Lentho' “Sang Pencukil”, Bentara Budaya, Yogyakarta, 3 11 Agustus 2011.

\section{Pustaka Laman}

www.outoftheboxindonesia.wordpress.com.

(Diakses pada Januari 2013, pukul 16.22) 